\title{
Sensitivity analysis of a model for direct reduction in swelling coal char-hematite composite pellets
}

E. Donskoi D. L. S. McElwain* L. J. Wibberley ${ }^{\dagger}$

(Received 20 June 2001; revised 14 January 2003)

\begin{abstract}
This paper describes a study of the optimisation of the modelling of the direct reduction process in swelling coal char-hematite composite pellets. Approximations of important physical parameters such as heats of reaction, specific heat and thermal conductivity of the reducing mixture have been developed. Without introducing significant errors, the computation time can be halved. The effect of the determination of pellet size and of the activation energies of the reducing reactions on the modelling results has also been investigated.
\end{abstract}

${ }^{*}$ CiSSaIM, School of Mathematical Sciences, Queensland University of Technology, Brisbane, Qld 4001, Australia.

mailto:e.donskoi@fsc.qut.edu.au

${ }^{\dagger}$ BHP Minerals Technology, Shortland, NSW 2307, Australia.

${ }^{0}$ See http://anziamj . austms.org.au/V44/CTAC2001/Dons for this article, (C) Austral. Mathematical Soc. 2003. Published 1 April 2003. ISSN 1446-8735 


\section{Contents}

1 Introduction

C141

2 Approximate modelling of heats of reactions

3 Approximate modelling of specific heats

C146

4 Approximate modelling of thermal conductivity

C149

5 Approx heats of reactions, specific heat and thermal conductivity

C150

6 Effect of pellet radius measurement on the predictions

C151

7 Sensitivity of the results to activation energy determination

C154

8 Conclusion

C156

References

C156

A Mathematical model of direct reduction

C157

\section{Introduction}

Some coal-based direct reduction processes are based on production of composite pellets consisting of a mixture of fines of iron-bearing oxide, carbonaceous material (coal, coke, char) and small amount of binder. The pellets are heated and reductant gases, volatile matter from the coal and carbon monoxide from the Boudouard reaction 
(see below), react with iron oxide and reduce the iron ore to iron. The main reactions for the coal based direct reduction are:

1. hematite to magnetite, $3 \mathrm{Fe}_{2} \mathrm{O}_{3}+\mathrm{CO}=2 \mathrm{Fe}_{3} \mathrm{O}_{4}+\mathrm{CO}_{2}$;

2. magnetite to wustite, $1.202 \mathrm{Fe}_{3} \mathrm{O}_{4}+\mathrm{CO}=3.807 \mathrm{Fe}_{0.947} \mathrm{O}+$ $\mathrm{CO}_{2}$

3. wustite to iron, $\mathrm{Fe}_{0.947} \mathrm{O}+\mathrm{CO}=0.947 \mathrm{Fe}+\mathrm{CO}_{2}$;

4. Boudouard reaction: $\mathrm{C}+\mathrm{CO}_{2}=2 \mathrm{CO}$.

Seaton et al. $[5,6]$, in their experiments with hematite and magnetite pellets containing coal char, showed that the difference in temperature between the pellet centre and the surface can be quite significant. This is associated with the highly endothermic nature of the carbon gasification reaction 4 . Their work and that of Nascimento et al. [4] showed that catastrophic swelling during the reduction can occur. A mathematical model of this process (see Appendix A) has been developed (Donskoi and McElwain [1]) and verified (see Figs. 1 and 2) using experimental data reported by Seaton et al. $[5,6]$.

Industrial processes for the direct reduction of iron ore in composite pellets are very complicated and involve non-uniform heating, nonisothermal heterogeneous reactions, devolatilization of coal and change in pellet size. Accurate two dimensional modelling of the reduction in a single pellet can take several days to run and modelling of industrial processes where multiple layers of pellets and reactions in the gas media outside the pellets should be included can be very time consuming. However, industry needs not only to model the process but to optimise it as well. This includes finding the optimal size of the pellets, the number of pellet layers and the optimal composition, for example. Thus the modelling of the reduction in 


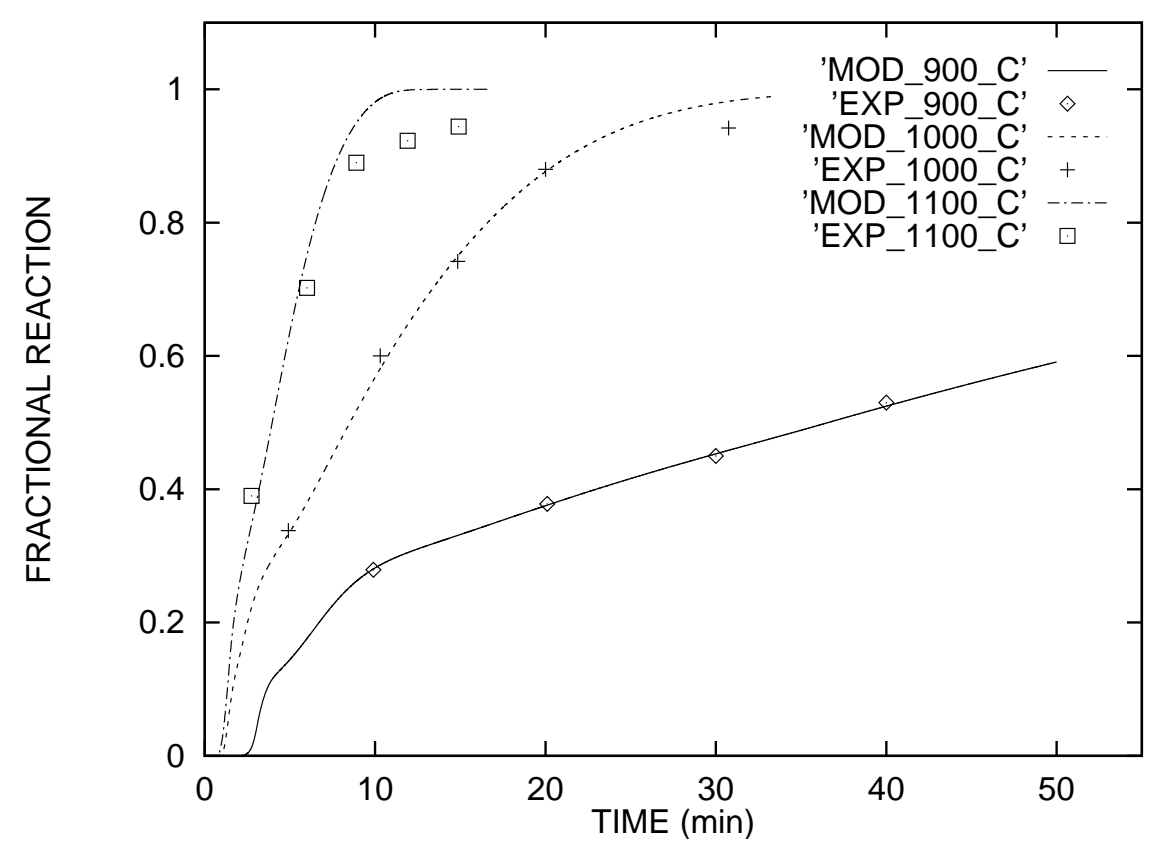

Figure 1: Fractional reaction vs. time for hematite pellets. Experimental and modelling results for three different furnace temperatures $900^{\circ} \mathrm{C}, 1000^{\circ} \mathrm{C}$ and $1100^{\circ} \mathrm{C}$. These and later experimental results were reproduced from work by Seaton et al. [5, 6]. 
(a)

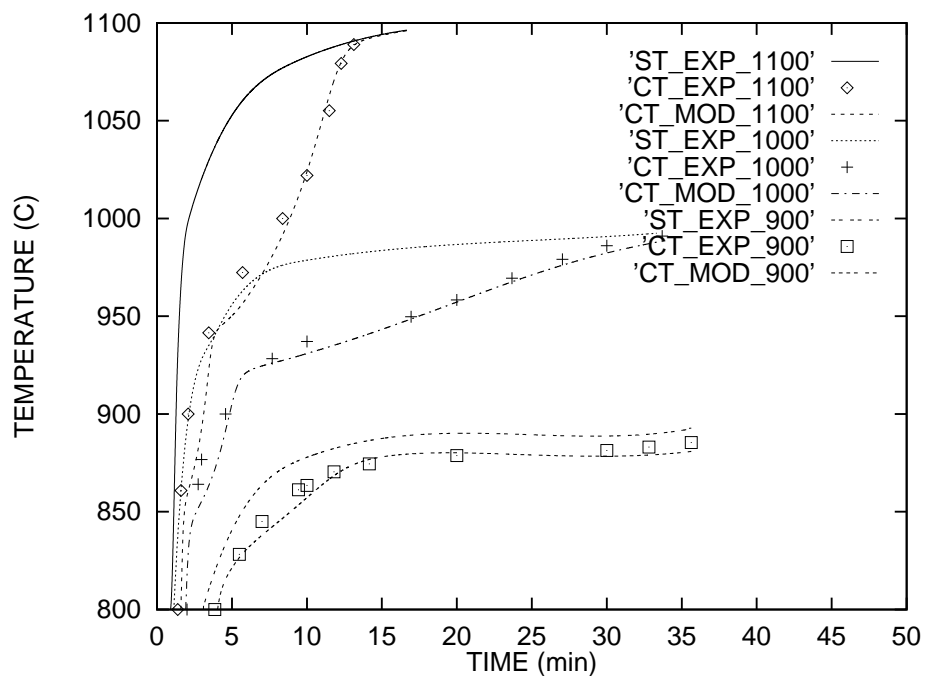

(b)

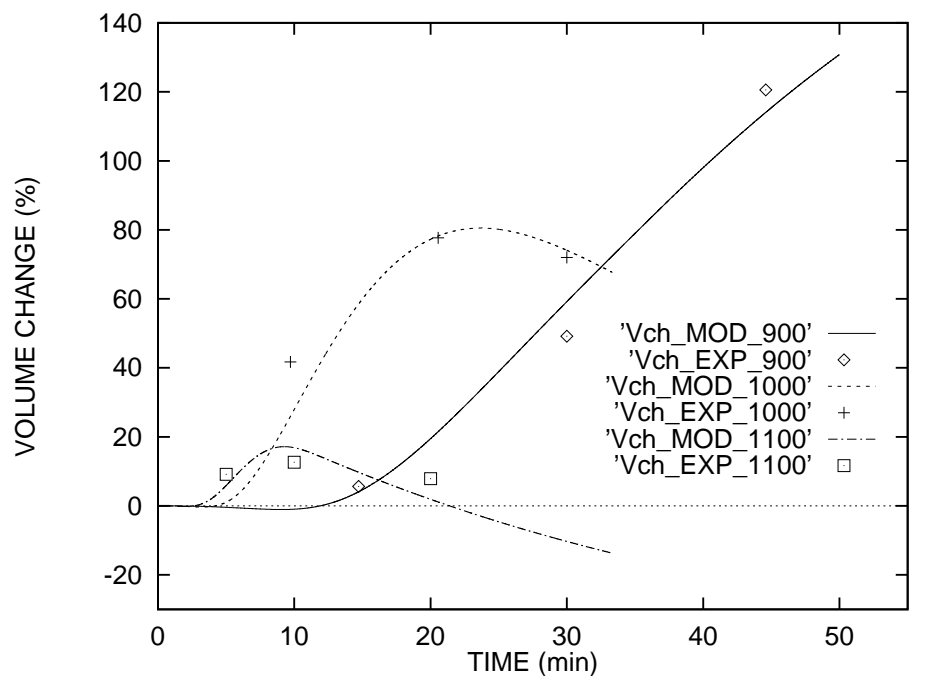

Figure 2: (a) Surface (ST) and core (CT) temperatures vs. time during the reduction. Abbreviations 'EXP' and 'MOD' are for experimental and modelling results, respectively. (b) Percentage volume change vs. time for three different furnace temperatures: $900^{\circ} \mathrm{C}$, $1000^{\circ} \mathrm{C}$ and $1100^{\circ} \mathrm{C}$. 
TABLE 1: Mean heats of reactions. For the reactions 1, 2 and 3, $\overline{\Delta H}$ is given per mole of carbon monoxide, whereas for the reaction $4, \overline{\Delta H}$ is given per mole of carbon.

\begin{tabular}{|c|cccc|}
\hline Reaction & 1 & 2 & 3 & 4 \\
\hline Temp. range $(\mathrm{K})$ & $700-1300$ & $900-1400$ & $1000-1400$ & $700-1400$ \\
$\overline{\Delta H}(\mathrm{~kJ} / \mathrm{mol})$ & -39.24 & 23.57 & -17.22 & 169.95 \\
\hline
\end{tabular}

one pellet should be as fast as possible. All the parameters in the modelling are temperature dependent and therefore time dependent (Donskoi and McElwain [2]). It is very important to understand the sensitivity of the model predictions to any simplification or inaccurate parameter estimation.

\section{Approximate modelling of heats of reactions}

Heats of reaction in the model of direct reduction in highly swelling coal char - iron ore composite pellet are modelled by

$$
H_{r}=A+B 10^{3} T^{-1}+C 10^{-3} T+D 10^{-6} T^{2}+E 10^{-9} T^{3} \mathrm{~kJ} / \mathrm{mol},
$$

and for different temperature ranges the coefficients are different [2].

As an approximation, we use a mean heat of reaction (see Table 1) for a certain reaction over a specified temperature range where this reaction is important. In Table 2, the maximum differences (per cent) for the predictions of modelling with mean heats of reactions and the full temperature dependent heats of reaction are given. Of course, the temperature ranges for the averaging can be dependent on the furnace temperature which gives better approximation but, 
TABLE 2: The maximum differences (per cent) for the modelling with mean heats of reactions and with temperature dependent heats of reaction.

\begin{tabular}{|c|ccc|}
\hline Temp $(\mathrm{C})$ & 900 & 1000 & 1100 \\
\hline Frac. reaction & -0.027 & -0.063 & -0.16 \\
Volume change & -0.094 & 0.22 & 0.19 \\
\hline
\end{tabular}

as will be seen, the errors are quite small even without this adjustment.

\section{Approximate modelling of specific heats}

To estimate the specific heats for every compound in the mixture for a certain temperature range, the following formula is used [1]:

$$
C_{p}=A+B 10^{6} T^{-2}+C 10^{-3} T+D 10^{-6} T^{2}+E 10^{-9} T^{3} \mathrm{~J} / \mathrm{mol} / \mathrm{K} .
$$

The approximation studied here does not use this expression for every compound, nor does it use a mean for each compound but uses a mean specific heat during the reduction for the whole mixture and it is calculated to be $914.5 \mathrm{~J} / \mathrm{kg} / \mathrm{K}$ approximately. Table 3 shows the maximum differences (per cent) for fractional reaction and volume change for modelling in cases when the average specific heat of the mixture is used and for the case where specific heat for every compound is given by Formula (2) above. See the errors associated with such modelling are smaller than the experimental errors. What is important is that the maximum difference for fractional reaction between the two approaches occurs during the earlier stages of the 
TABLE 3: Maximum differences (per cent) in predictions using modelling between cases when the average specific heat of mixture is used and for the case where the specific heat is modelled for every compound as a temperature dependent function.

\begin{tabular}{|c|ccc|}
\hline Temp (C) & 900 & 1000 & 1100 \\
\hline Frac. reaction & 0.61 & 1.15 & 1.27 \\
Volume change & 0.18 & 0.45 & 0.38 \\
\hline
\end{tabular}

reduction and decreases significantly closer to the middle of the reduction (see Fig. 3). For example, for a reduction temperature of $1000^{\circ} \mathrm{C}$ this maximum occurs after $1.48 \mathrm{~min}$. from the beginning of the reduction but, after $5 \mathrm{~min}$. of reduction, the error for the fractional reaction decreases from $1.15 \%$ to $0.17 \%$.

Another approximation to the specific heat of the mixture involves the introduction of a local characteristic of the degree of reduction, namely the amount of oxygen removed relative to pure hematite $O_{r}$ : for pure hematite it is zero; and for completely reduced iron ore it is unity. Using the values for the temperatures of $900^{\circ} \mathrm{C}, 1000^{\circ} \mathrm{C}$ and $1100^{\circ} \mathrm{C}$, a multiple regression for the specific heat of the mixture as a function of temperature and amount of oxygen removed $O_{r}$ gave

$$
\begin{aligned}
C_{p}^{m}= & 1.76411 T-0.000686059 T^{2}+1.40233 / O_{r} \\
& -464.569 O_{r}+150.852 O_{r}^{2} .
\end{aligned}
$$

The modelling was repeated using this formula for the specific heat of the mixture and maximum differences between the predictions for the simplified model and full model are shown in Table 4. See the errors for the predicted fractional reaction is of the order of $0.1 \%$ and for the volume change the errors are less than $0.02 \%$. We conclude that such approximations are quite acceptable. 


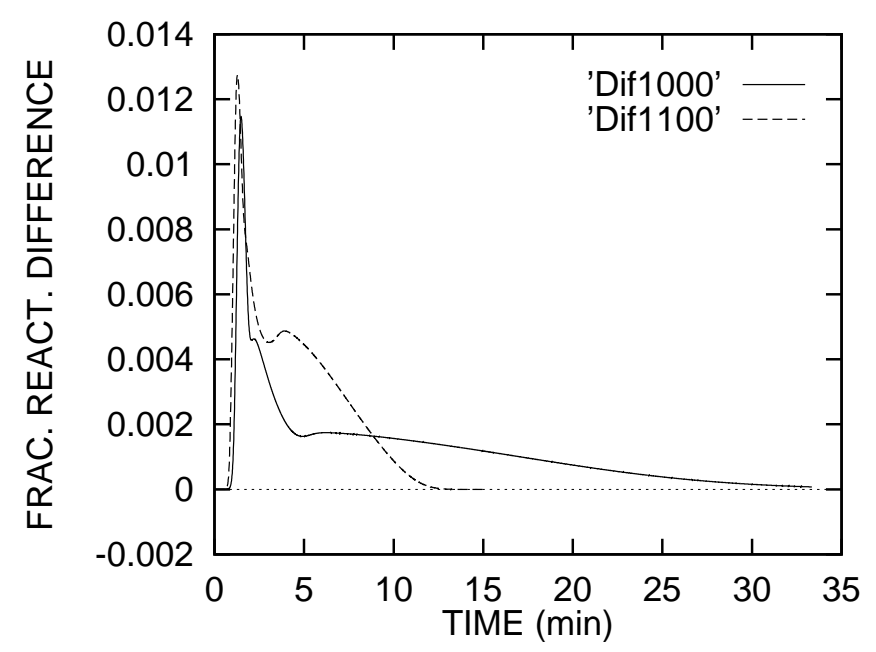

FIGURE 3: Difference in fractional reaction modelling between cases when the average specific heat of mixture is used and for the case where the specific heat is modelled for every compound as temperature-dependent function.

TABle 4: Maximum differences (per cent) in modelling between cases when the specific heat of mixture was modelled as function of temperature and oxygen removed and the case where the specific heat is modelled for every compound as temperature dependent function.

\begin{tabular}{|c|ccc|}
\hline Temp $(\mathrm{C})$ & 900 & 1000 & 1100 \\
\hline Frac. reaction & 0.092 & 0.085 & 0.11 \\
Volume change & 0.0023 & 0.0062 & 0.015 \\
\hline
\end{tabular}


TABLE 5: Maximum differences (per cent) in modelling between cases when the average thermal conductivity of mixture is used and for the case where the thermal conductivity is modelled with Formula (4).

\begin{tabular}{|c|ccc|}
\hline Temp (C) & 900 & 1000 & 1100 \\
\hline Frac. reaction & -2.27 & -3.94 & -5.07 \\
Volume change & -3.16 & -4.04 & 3.78 \\
\hline
\end{tabular}

\section{Approximate modelling of thermal conductivity}

The thermal conductivity in the model of direct reduction in highly swelling coal char - iron ore composite pellet is modelled as

$$
k_{m}=\frac{2}{3}\left\{\phi / k_{g}+(1-\phi) / k_{s}\right\}^{-1}+\frac{1}{3}\left\{\phi k_{g}+(1-\phi) k_{s}\right\},
$$

where $\phi$ is the porosity, $k_{g}$ is the thermal conductivity of gas inside the pores of the solid and $k_{s}$ is the mean dense thermal conductivity of the mixture. The formula for the dense thermal conductivity used in this modelling is

$$
k_{s}=c \sum_{i} f_{i} k_{s i}
$$

where $f_{i}$ is volume fraction of the solid component $i, k_{s i}$ is the thermal conductivity of the solid component $i$. The adjusting factor $c$, reflects the effects of consolidation, the porosity matrix and the mixture of different components in the solid fraction. The thermal conductivity of each compound is modelled as a temperature dependent function. Modelling using an average thermal conductivity gives quite poor results, see Table 5 . See the errors of such 
TABLE 6: Maximum differences (per cent) in modelling between cases when the thermal conductivity is approximated as function of temperature and amount of oxygen removed and for the case where thermal conductivity is modelled with Formula (4).

\begin{tabular}{|c|ccc|}
\hline Temp (C) & 900 & 1000 & 1100 \\
\hline Frac. reaction & 0.31 & 0.37 & 1.46 \\
Volume change & -0.95 & 0.83 & 1.2 \\
\hline
\end{tabular}

an approximation are significant and increase with reduction temperature.

We now seek a similar regression to the approximation of the thermal conductivity as was used for the specific heat approximation - to approximate the local value of the thermal conductivity of the mixture as the function of the temperature and the amount of oxygen removed in comparison with pure hematite. The model is

$$
\begin{aligned}
k_{m}= & 2.24752-0.00223533 T+9.88274 \times 10^{-10} T^{3} \\
& -3.83744 O_{r}+4.88544 O_{r}^{2}-1.999985 O_{r}^{3} .
\end{aligned}
$$

The results of such modelling are shown in Table 6. See the errors in the predictions have been significantly decreased.

\section{$5 \quad$ Modelling with approximated heats of reactions, specific heat and thermal conductivity}

The results of using previously reported approximations (specific heat and thermal conductivity approximated with functions of tem- 
TABLE 7: Maximum differences (per cent) in predictions between cases when the heats of reactions, specific heat and thermal conductivity is approximated and when they are calculated according to formulae (1), (2) and (4) respectively.

\begin{tabular}{|c|ccc|}
\hline Temp (C) & 900 & 1000 & 1100 \\
\hline Frac. reaction & -0.32 & 0.33 & 1.38 \\
Volume change & -1.03 & 0.86 & 1.26 \\
\hline
\end{tabular}

perature and amount of oxygen removed and mean heats of reactions) in the modelling are shown in Table 7 . These prediction errors are quite acceptable. In addition, we conclude that the overall specific heat and thermal conductivity of the mixture can be modelled as functions of temperature and amount of oxygen removed. This significantly simplifies the modelling. Modelling using the full temperature dependent formulae for a temperature of $1000^{\circ} \mathrm{C}$ for a one dimensional case takes (on a Digital Alpha Server 2100) about $11 \mathrm{~min} .50 \mathrm{sec}$. while with approximated parameters it takes 5 min. 55 sec. which represents a $50 \%$ saving in computer time.

\section{Effect of pellet radius measurement on the predictions}

Pelleting does not produce a narrow size range of pellets. Their radii can differ by a factor of two. How applicable are the predictions of the model if the size of the pellet in the model is different from the size of the pellet in the experiment? Is it appropriate to use an average pellet size? Table 8 shows the maximum difference for the fractional reaction (per cent) and percentage volume change for 
TABLE 8: Maximum differences for the fractional reaction (per cent) and percentage of volume change during the reduction between parameters corresponding to pellets of $5 \mathrm{~mm}$ and $9 \mathrm{~mm}$ and the pellet of radius $7 \mathrm{~mm}$.

\begin{tabular}{|l|l|rrr|}
\hline & radius \Temp (C) & 900 & 1000 & 1100 \\
\hline Fractional & $5 \mathrm{~mm}$ & 1.87 & 6.08 & 10.8 \\
Reaction & $9 \mathrm{~mm}$ & -2.25 & -6.38 & -9.83 \\
\hline Volume & $5 \mathrm{~mm}$ & 6.67 & -18.3 & -8.58 \\
change & $9 \mathrm{~mm}$ & -8.59 & 21.9 & 10.4 \\
\hline
\end{tabular}

pellets of radius $5 \mathrm{~mm}$ and $9 \mathrm{~mm}$ compared with a pellet of radius $7 \mathrm{~mm}$ during the reduction.

See from the Table 8 the difference between predicted results compared with those for $7 \mathrm{~mm}$ pellets for the fractional reaction increases with temperature and can be quite significant (see Fig. 4). The predicted differences in volume change are also significant.

In an industrial process there is a range of pellet sizes. Let us calculate the difference between the predictions in a situation where there is one third by weight of each pellet sizes $-5 \mathrm{~mm}, 7 \mathrm{~mm}$ and $9 \mathrm{~mm}$ and the situation where all pellets are $7 \mathrm{~mm}$. Table 9 shows the maximum error for modelling the process with an average size pellet. The above analysis has shown the magnitude of the error associated with such pellet size averaging and each researcher needs to decide whether this modelling error is acceptable. 


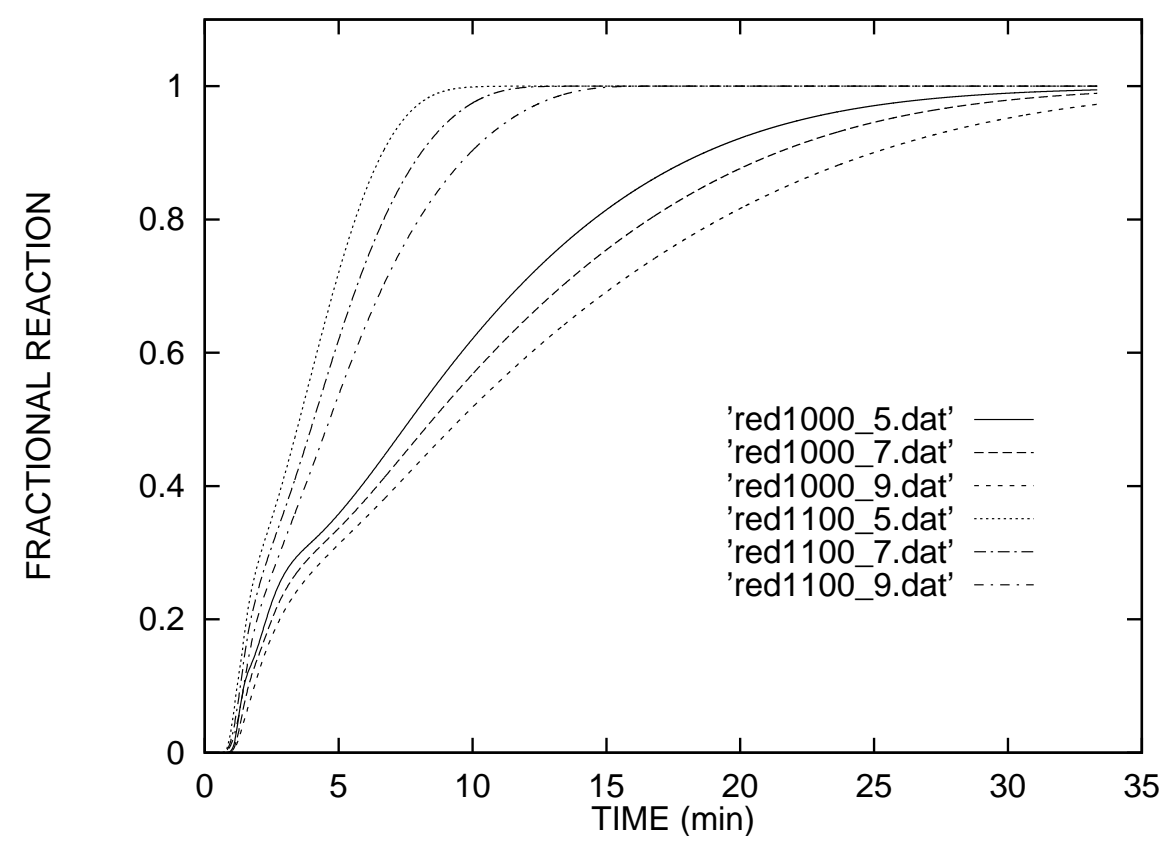

Figure 4: Fractional reaction modelling for pellet sizes of $5 \mathrm{~mm}$, $7 \mathrm{~mm}, 9 \mathrm{~mm}$ with reduction temperatures of $1000^{\circ} \mathrm{C}$ and $1100^{\circ} \mathrm{C}$.

TABLE 9: Maximum difference (per cent) in fractional reaction and volume change for situation where one third of pellets by weight are $5 \mathrm{~mm}, 7 \mathrm{~mm}, 9 \mathrm{~mm}$ in radius compared with modelling when all pellets are $7 \mathrm{~mm}$ in radius.

\begin{tabular}{|c|ccc|}
\hline Temp $(\mathrm{C})$ & 900 & 1000 & 1100 \\
\hline Frac. reaction & -0.15 & -0.68 & -1.60 \\
Volume change & -0.77 & -2.66 & -2.26 \\
\hline
\end{tabular}


TABLE 10: The maximum differences with original modelling for fractional reaction and volume change for reactions 1, 2 and 3 with activation energies $370 \mathrm{~kJ} / \mathrm{mol}, 400 \mathrm{~kJ} / \mathrm{mol}$ and $320 \mathrm{~kJ} / \mathrm{mol}$ respectively.

\begin{tabular}{|l|l|rrr|}
\hline & reaction \Temp $(\mathrm{C})$ & 900 & 1000 & 1100 \\
\hline Fractional & 1 & 2.01 & 1.26 & 1.16 \\
reaction & 2 & 4.98 & 3.10 & 1.82 \\
& 3 & 24.1 & 18.5 & 13.5 \\
\hline Volume & 1 & 0.06 & 0.10 & 0.08 \\
change & 2 & 3.38 & 1.55 & 0.57 \\
& 3 & -87.0 & -28.7 & 5.04 \\
\hline
\end{tabular}

\section{Sensitivity of the results to activation energy determination}

The values for the frequency factors and for the apparent activation energies for the first, second and third reactions are the following [1]:

- $k_{H}=6.0 \times 10^{17} \mathrm{~s}^{-1}, E_{H}=380 \mathrm{~kJ} / \mathrm{mol}$;

- $k_{M}=7.5 \times 10^{16} \mathrm{~s}^{-1}, E_{M}=410 \mathrm{~kJ} / \mathrm{mol}$;

- $k_{W}=1.7 \times 10^{11} \mathrm{~s}^{-1}, E_{M}=330 \mathrm{~kJ} / \mathrm{mol}$.

In this section the effect of the poor estimation of the activation energy is investigated. The activation energy for each reaction 1 , 2 and 3 has been decreased by $10 \mathrm{~kJ} / \mathrm{mol}$ (one at a time) while the predicted activation energies for other reactions remains the same. The maximum differences between the new predictions and the original modelling are shown in Table 10. See in Table 10 and 
(a)

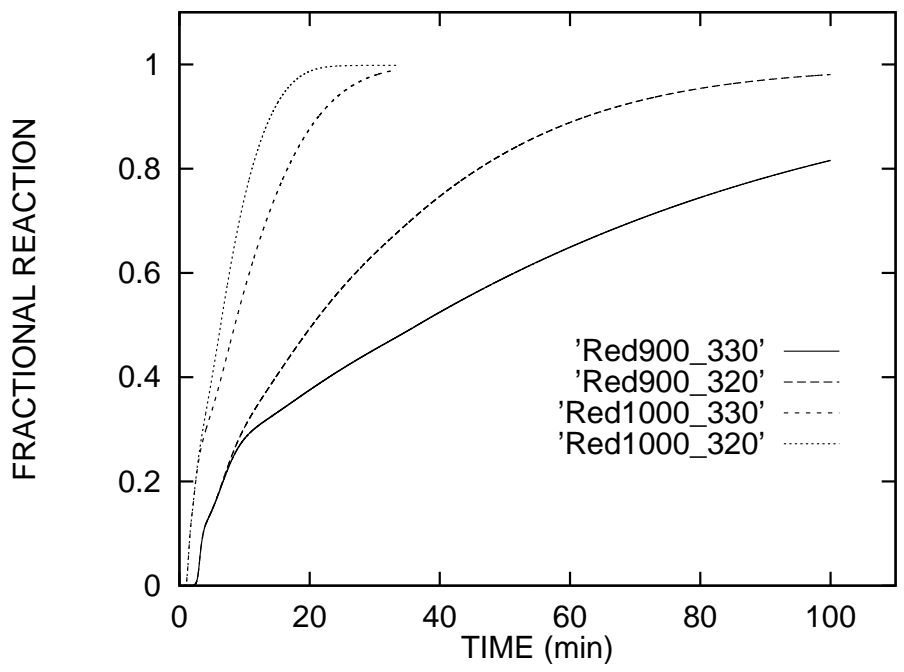

(b)

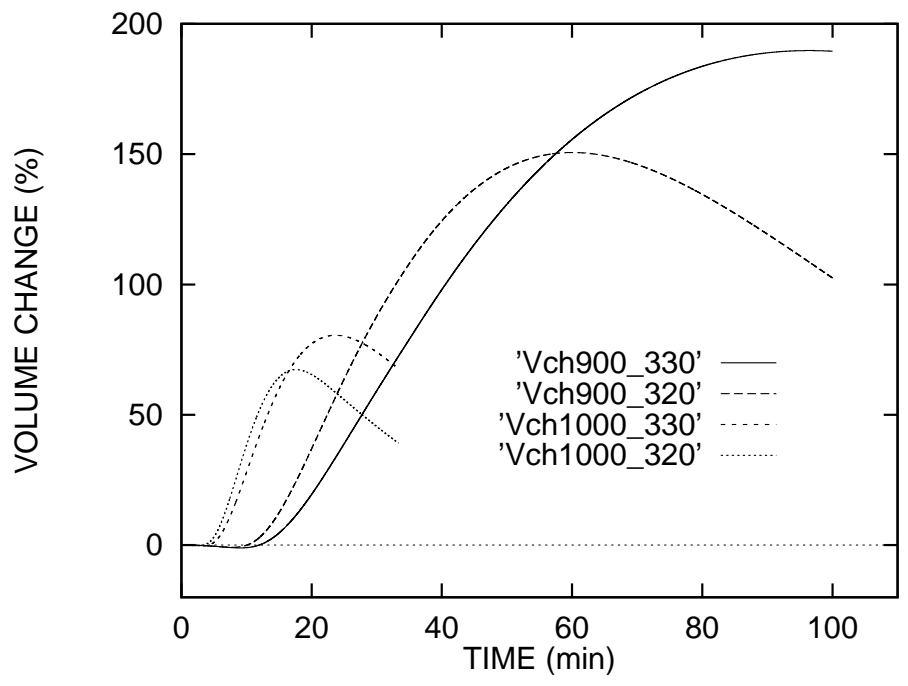

FIGURE 5: Mathematical modelling of fractional reaction and volume change for original case with activation energy of reaction 3 is $E_{M}=330 \mathrm{~kJ} / \mathrm{mol}$ and for the second case when $E_{M}=320 \mathrm{~kJ} / \mathrm{mol}$ for temperatures $900^{\circ} \mathrm{C}$ and $1000^{\circ} \mathrm{C}$. 
Fig. 5 that whereas the accurate determination of the activation energies for the first two reactions are not so important, the accurate determination of activation energy for the third reaction is critical, especially for low reduction temperatures.

\section{Conclusion}

We have studied the way in which the mathematical modelling of highly swelling composite pellets can be optimised without a significant loss of accuracy. The specific heat and the thermal conductivity of the mixture has been shown to be modelled as functions of temperature and amount of oxygen removed. This significantly simplifies the modelling. Instead of temperature dependent functions, averaged heats of reactions can be used. The computation time of modelling using such approximations is significantly decreased by a factor of two. Averaging over the pellet size does not significantly affect the modelling prediction. The accurate determination of activation energy for the wustite to iron reaction is critical for the modelling.

\section{References}

[1] E. Donskoi and D. L. S. McElwain. Mathematical Modelling of Nonisothermal Reduction in a Highly Swelling Iron Ore-Coal Char Composite Pellet (in press) Ironmaking and Steelmaking C142, C146, C154, C157

[2] E. Donskoi and D. L. S. McElwain. Estimation and Modelling of Parameters for Direct Reduction in Iron Ore/Coal 
Composites submitted to Metallurgical and Materials Transactions C145

[3] E. Donskoi and D. L. S. McElwain. Approximate Modelling of Coal Pyrolysis. FUEL, 78, 825-835, 1999 C158

[4] R. C. Nascimento, M. B. Mourao, and J. D. T. Capocchi. Kinetics and Catastrophic Swelling During Reduction of Iron Ore in Carbon Bearing Pellets. Ironmaking Steelmaking, 26, (3), 182-186, 1999. C142

[5] C. E. Seaton, J. S. Foster and J. Velasco. Reduction Kinetics of Hematite and Magnetite Pellets Containing Coal Char. Transactions ISIJ, 23, 490-496, 1983. C142, C143

[6] C. E. Seaton, J. S. Foster and J. Velasco. Structural Changes Occurring during Reduction of Hematite and Magnetite Pellets Containing Coal Char. Transactions ISIJ, 23, 497-503, 1983. C142, C143

\section{A Mathematical model of direct reduction in hematite-coal char composite pellet}

The model includes seven differential equations as outlined in Donskoi and McElwain [1]. We present a summary here.

The first equation is the one-dimensional non-linear diffusion equation for temperature with a sink term corresponding to the loss of heat to fuel the reactions:

$$
\sum_{l}\left(\rho_{l} c_{l}\right) \frac{\partial T}{\partial t}=\frac{1}{r^{2}}\left\{\frac{\partial}{\partial r}\left[k r^{2} \frac{\partial T}{\partial r}\right]\right\}-\sum_{j} H_{j} R_{j}
$$


where $T$ is the temperature, $c_{l}$ and $\rho_{l}$ are the specific heat and the partial density of the $l$ th compound in the mixture, $k$ is the thermal conductivity, which is a function of composition, porosity and temperature and $H_{j}$ and $R_{j}$ the heat and the rate of $j$ th reaction, respectively.

Three other equations are for transitions from hematite $H$, to magnetite $M$, magnetite to wustite $W$, and wustite to iron $F,(H$, $M, W$ and $F$ in $\mathrm{kg} / \mathrm{m}^{3}$ ).

$$
\begin{aligned}
\frac{d H}{d t} & =-H k_{H} \exp \left(-E_{H} /(R T)\right) \\
\frac{d M}{d t} & =x H k_{H} \exp \left(-E_{H} /(R T)\right)-M k_{M} \exp \left(-E_{M} /(R T)\right) \\
\frac{d W}{d t} & =y M k_{M} \exp \left(-E_{M} /(R T)\right)-W k_{W} \exp \left(-E_{W} /(R T)\right)(10) \\
\frac{d F}{d t} & =z W k_{W} \exp \left(-E_{W} /(R T)\right)
\end{aligned}
$$

where $x, y$ and $z$ are the weight coefficients, $k_{H}, k_{M}$ and $k_{W}$ are the apparent frequency factors, and $E_{H}, E_{M}$ and $E_{W}$ are apparent activation energies, all constant.

The fifth equation is for the carbon consumption:

$$
\begin{aligned}
\frac{d C}{d t}= & -Q_{H} H k_{H} \exp \left(-E_{H} /(R T)\right)-Q_{M} M k_{M} \exp \left(-E_{M} /(R T)\right) \\
& -Q_{W} W k_{W} \exp \left(-E_{W} /(R T)\right),
\end{aligned}
$$

where $Q_{H}, Q_{M}$ and $Q_{W}$ are coefficients depending on weight relationships and equilibrium conditions for a corresponding reaction.

The next equation is for the modelling of devolatilisation of coal char. It uses the concept of $n$th order reaction modelling [3]:

$$
\frac{d V_{v}}{d t}=k_{0} \exp \left(-E_{A} /(R T)\right)\left(V_{v}^{*}-V_{v}\right)^{n}
$$


where $V_{v}$ is the mass fraction of volatiles from the coal char evolved up to time $t, V_{v}^{*}$ is the value of $V_{v}$ as $t \rightarrow \infty, k_{0}$ is the pre-exponential factor, $E_{A}$ is the apparent activation energy, $n$ is the order of the reaction, $R$ is the ideal gas constant, and $T$ is the absolute temperature.

The last equation describes the local volume change. This process has been modelled as the interaction between two opposite processes: swelling (term $S w$ ) and shrinkage (term $S h$ ).

$$
\frac{d V}{d t}=V(S w-S h) .
$$

The shrinkage term is modelled as:

$$
S h=0.012 \phi^{2} \exp (-4372 / T) .
$$

where $\phi$ is the porosity and $T$ is the absolute temperature. The swelling term is modelled as:

$$
S w=2.9 \times 10^{-7} \frac{W F}{\sigma} \exp \left(\frac{-\left(T-T_{0}\right)^{2}}{2 \sigma^{2}}\right) .
$$

where $W$ and $F$ are concentrations of wustite and iron and $T$ is the absolute temperature. As can be seen the swelling term has Gaussian dependence on temperature with a mean temperature, $T_{0}$, of $1193^{\circ} \mathrm{K}$ and a standard deviation, $\sigma$, of $60^{\circ} \mathrm{K}$. As a result of the local volume change the total change of the pellet size occurs. 